\title{
Suppression of the Plant-Parasitic Nematode Heterodera schachtii by the Fungus Dactylella oviparasitica
}

\author{
Rabiu Olatinwo, Bei Yin, J. Ole Becker, and James Borneman
}

First, second, and fourth authors: Department of Plant Pathology, and third author: Department of Nematology, University of California, Riverside 92521.

Accepted for publication 27 September 2005.

\section{ABSTRACT}

Olatinwo, R., Yin, B., Becker, J. O., and Borneman, J. 2006. Suppression of the plant-parasitic nematode Heterodera schachtii by the fungus Dactylella oviparasitica. Phytopathology 96:111-114.

This study examined the role of the fungi Dactylella oviparasitica and Fusarium oxysporum in the beet-cyst nematode (Heterodera schachtii) suppressiveness exhibited by a southern Californian soil. In prior research, the abundance of $D$. oviparasitica rRNA genes positively correlated with high levels of suppressiveness, whereas the abundance of F. oxysporum rRNA genes positively correlated with minimal to moderate levels of suppressiveness. In this report, both fungi were added to fumigation-induced nonsuppressive soil, planted with Swiss chard, and infested with $H$. schachtii juveniles. After two nematode generations, $D$. oviparasitica strain 50 reduced the population densities of $H$. schachtii eggs and juveniles to those in the suppressive soil and $H$. schachtii cysts to levels lower than in the suppressive soil. F. oxysporum did not significantly reduce $H$. schachtii populations. These results suggest that $D$. oviparasitica strain 50 plays a major role in the suppression of $H$. schachtii population development in this southern Californian soil.
Prior research identified a southern California soil that suppresses the population development of the beet-cyst nematode Heterodera schachtii. The biological nature of this suppressiveness was demonstrated by preplant treatments with various fumigants (metam-sodium, methyl bromide, and methyl iodide) or aerated steam, which diminished the suppressiveness to undetectable levels in greenhouse and field studies $(13,14)$. Another demonstration of its biological nature was achieved by amendment of $1 \%$ suppressive soil into a fumigation-induced, nonsuppressive field site (14). In addition, treatment of the soil at $55^{\circ} \mathrm{C}$ for $30 \mathrm{~min}$ also removed the $H$. schachtii suppressiveness (15). Even more important for our investigations, cysts that developed in the suppressive soil transferred the suppressiveness to fumigation-induced, nonsuppressive soil (15). This demonstrated that the suppressive factor or factors were in the cysts, making subsequent investigations to identify these factors a more feasible task.

To identify fungi involved in this $H$. schachtii suppressiveness, we employed a three-phased approach: (i) identification of microorganisms whose population levels correlate with the suppressiveness through extensive rRNA gene analysis, (ii) validation of the population trends with quantitative polymerase chain reaction (qPCR) analyses, and (iii) reintroduction of the microorganisms into the environment to assess their functions. In the first phase of the project, oligonucleotide fingerprinting of ribosomal RNA genes (OFRG) $(2,11,12)$ was used to identify fungal rRNA genes found in $H$. schachtii cysts isolated from soils possessing various levels of suppressiveness (16). Five soil treatments with various levels of suppressiveness, generated by mixing different amounts of suppressive and fumigation-induced nonsuppressive soil, were planted with Brassica juncea and infested with second-stage juveniles (J2) of H. schachtii. After two nematode generations, rRNA gene sequences that were more abundant in cysts isolated from the highly suppressive soils than in cysts from the less-suppres-

Corresponding author: J. Borneman; E-mail address: borneman @ucr.edu

DOI: 10.1094/PHYTO-96-0111

(c) 2006 The American Phytopathological Society sive soils were considered candidate sequences. In phase 2 , sequence-selective qPCR was used to determine the amounts of the candidate sequences in cysts from soils possessing various levels of suppressiveness, which were produced by mixing various quantities of suppressive and fumigation-induced nonsuppressive soil and by biocidal treatments. Phases 1 and 2 of this project led to the identification of genes with high sequence identity to Dactylella oviparasitica and Fusarium oxysporum rRNA genes, whose levels consistently and positively correlated with high and minimal to moderate levels of $H$. schachtii suppressiveness, respectively (16).

In this report, we describe the results from phase 3 of this project. Strains of D. oviparasitica and $F$. oxysporum were isolated from $H$. schachtii cysts collected from the suppressive soil and added to fumigation-induced, nonsuppressive soil to determine whether they can produce $H$. schachtii suppressiveness.

\section{MATERIALS AND METHODS}

Extraction of $\boldsymbol{H}$. schachtii cysts from soil. Soil from $H$. schachtii-suppressive soil, field 9E located at the University of California-Riverside Agricultural Research Station (13), was air dried for 2 days at room temperature to facilitate cyst extraction. $H$. schachtii cysts were extracted as previously described (16).

Fungal isolation from $\boldsymbol{H}$. schachtii cysts. Individual cysts were placed in $1.5-\mathrm{ml}$ microcentrifuge tubes and washed by adding $100 \mu \mathrm{l}$ of sterile distilled water, mixing with a vortex mixer for $5 \mathrm{~s}$, and removing the water by pipetting. Cysts were surface sterilized by adding $100 \mu \mathrm{l}$ of $0.6 \% \mathrm{NaOCl}$, mixing with a vortex mixer for $90 \mathrm{~s}$, and then removing the bleach solution by pipetting. Individual cysts were placed in separate microcentrifuge tubes containing $100 \mu \mathrm{l}$ of sterile distilled water and crushed with a pipette tip. Crushed cyst mixtures were spread with a sterile glass rod on water agar containing rifampicin $(10 \mu \mathrm{g} / \mathrm{ml})$. After $24 \mathrm{~h}$ at room temperature, individual colonies were examined as described below.

Fungal identification and the fungal strains used in this study. Portions of each fungal colony were collected with a sterile 
toothpick and placed in 1.5-ml microcentrifuge tubes containing $10 \mu \mathrm{l}$ of sterile water. Mycelia were crushed with a pipette tip and homogenized by mixing with a vortex mixer for $30 \mathrm{~s}$. The resulting mixtures were centrifuged for $1 \mathrm{~min}$ at $14,000 \times \mathrm{g}$. Supernatants from individual colonies were subjected to $F$. oxysporumand $D$. oviparasitica-selective PCR analysis. Amplification reactions (10 $\mu$ l total volume) were performed in glass capillary tubes

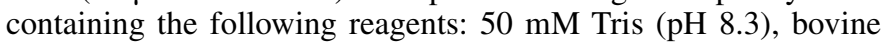
serum albumen at $500 \mu \mathrm{g} / \mathrm{ml}, 2.5 \mathrm{mM} \mathrm{MgCl}, 250 \mu \mathrm{M}$ each dNTP, $400 \mathrm{nM}$ each primer, $1 \mu \mathrm{l}$ of supernatant from the fungal colonies, and 0.5 units of Taq DNA polymerase. For the F. oxysporumselective PCR, which targeted the small-subunit (SSU) rRNA gene, the primers were FusF, GTATTGCTTTGGCAGTA, and FusR, TTTCGGACAAGGAAGTA, and the cycling parameters were $94^{\circ} \mathrm{C}$ for $2 \mathrm{~min} ; 35$ cycles of $94^{\circ} \mathrm{C}$ for $10 \mathrm{~s}, 55^{\circ} \mathrm{C}$ for $15 \mathrm{~s}$, and $72^{\circ} \mathrm{C}$ for $20 \mathrm{~s}$; followed by $72^{\circ} \mathrm{C}$ for $2 \mathrm{~min}$ (16). D. oviparasitica-selective PCR was performed with one of two different primer sets. For the $D$. oviparasitica-selective PCR assay targeting the SSU rRNA gene, the primers were DactF, CAGGTCCAGACACATTA, and DactR, CTTTCGGCCAAGGATT, and the cycling parameters were $94^{\circ} \mathrm{C}$ for $2 \mathrm{~min} ; 35$ cycles of $94^{\circ} \mathrm{C}$ for $10 \mathrm{~s}, 60^{\circ} \mathrm{C}$ for $20 \mathrm{~s}$, and $72^{\circ} \mathrm{C}$ for $30 \mathrm{~s}$; followed by $72^{\circ} \mathrm{C}$ for 2 min (16). For the D. oviparasitica-selective PCR assay targeting the internal transcribed spacer (ITS) region, the primers were DactITSF, AAAACCCCCAAGTTGCTTC, and DactITSR, CCACTGTGCTGTTACAACC, and the cycling parameters were $94^{\circ} \mathrm{C}$ for $2 \mathrm{~min} ; 35$ cycles of $94^{\circ} \mathrm{C}$ for $15 \mathrm{~s}, 64^{\circ} \mathrm{C}$ for $15 \mathrm{~s}$, and $72^{\circ} \mathrm{C}$ for $20 \mathrm{~s}$; followed by $72^{\circ} \mathrm{C}$ for $2 \mathrm{~min}$. Thermal cycling was performed using a 1002 RapidCycler (Idaho Technology Inc., Salt Lake City, UT). Nucleotide sequences of the amplified PCR products were obtained using the PRISM BigDye Terminators Cycle Sequencing Kit (version 3.0; ABI, Foster City, CA) and a 3100 Genetic Analyzer (ABI). Colonies whose SSU rRNA gene sequences had $100 \%$ identity to the $F$. oxysporum and $D$. oviparasitica rRNA genes identified in a previous study (16) were saved for further study and subcultured on potato dextrose agar (PDA). Two of these colonies, $F$. oxysporum strain 471 and D. oviparasitica strain 50, were used in this study. D. oviparasitica strain Stirling (9), which was obtained from the University of CaliforniaRiverside Culture Collection of Nematode-Destroying Fungi (J. O. Becker, Curator), also was used in this study.

Fungus production. Petri plates $(10 \mathrm{~cm}$ in diameter) containing PDA were inoculated with individual 5-mm-diameter agar plugs containing one of the three following fungi: $F$. oxysporum strain $471, D$. oviparasitica strain 50 , or D. oviparasitica strain Stirling. These cultures were grown at room temperature for approximately 10 (F. oxysporum) and 21 (D. oviparasitica strains) days. For each plate, after the incubation period, the fungal culture and PDA medium were transferred to a Sunbeam 6 Speed Blender (Model 4142; Sunbeam Products Inc., Boca Raton, FL) containing $50 \mathrm{ml}$ of sterile water. The components were blended for $30 \mathrm{~s}$ using the "blend" setting. Then, $0.5 \mathrm{ml}$ of each mixture was used to estimate the inoculum concentrations by determining the number of CFU from a dilution series. The remaining portions of the fungal mixtures were added to soil (within $1 \mathrm{~h}$ of blending the fungi) as described below.

D. oviparasitica and $\boldsymbol{F}$. oxysporum greenhouse trials. Two replicate greenhouse trials were conducted to evaluate the ability of the fungal strains to suppress $H$. schachtii when added to nonsuppressive soil. The soil used in these studies was collected from the upper $10 \mathrm{~cm}$ of field $9 \mathrm{E}$. The $9 \mathrm{E}$ soil is a Hanford fine sandy loam (60.9\% sand, $29.6 \%$ silt, and 9.5\% clay; $\mathrm{pH} 8$ ) (13). After large aggregates were removed from the soil using a sieve with 6-mm openings, a portion $\left(\approx 18,000 \mathrm{~cm}^{3}\right)$ of the sieved soil was fumigated with $2 \mathrm{ml}$ of methyl iodide (100\%; DSM Fine Chemicals, Saddle Brook, NJ) in 19-liter polyethylene buckets for 4 days (1). Three weeks later, fumigated (nonsuppressive) and nonfumigated (suppressive) 9E soils each were mixed 10:1 with silica sand to facilitate water drainage during the greenhouse trials. The amount of soil used per pot $\left(\approx 1,600 \mathrm{~cm}^{3}\right)$ was standardized by filling $15-\mathrm{cm}$-diameter pots to $2.5 \mathrm{~cm}$ below the top. Fungal suspensions (described above) and the fumigationinduced nonsuppressive soil from each pot were combined in plastic bags, mixed by inverting the plastic bags, and returned to the pots. Two control soils (nonsuppressive and suppressive), which did not receive fungal inoculum, also were added to pots.

The treatments consisted of (i) F. oxysporum strain 471, (ii) D. oviparasitica strain 50, (iii) D. oviparasitica strain Stirling, (iv) 9E soil (positive control suppressive soil), (v) fumigated $9 \mathrm{E}$ soil (negative control nonsuppressive soil), and (vi) simultaneous addition of $D$. oviparasitica strain 50 and $H$. schachtii inoculum. For trial 1, fungal CFU/pot were D. oviparasitica strain 50 (treatments 2 and 6), $1.1 \times 10^{8} ; \mathrm{F}$. oxysporum strain 471 (treatment 1 ), $1.4 \times 10^{10}$; and D. oviparasitica strain Stirling (treatment 3), $2.9 \times$ $10^{7}$. For trial 2, fungal CFU/pot were $D$. oviparasitica strain 50 (treatments 2 and 6$), 1.0 \times 10^{8} ; F$. oxysporum strain 471 (treatment 1 ), $1.3 \times 10^{10}$; and D. oviparasitica strain Stirling (treatment 3), $2.9 \times 10^{7}$. All treatments were infested with $\mathrm{J} 2$ of $H$. schachtii 4 weeks after the addition of the fungal inoculum except for treatment (vi), where the fungus was added simultaneously with the $H$. schachtii inoculum in three holes $(\approx 3.0 \mathrm{~cm}$ deep and $1.5 \mathrm{~cm}$ wide) in the surface of the soil.

After fungal suspensions were added to the soil, each pot was sown with three seed of Swiss chard (Beta vulgaris; Lockhart Seeds, Stockton, CA). All pots were placed in a greenhouse under natural light at $23 \pm 3^{\circ} \mathrm{C}$ in a randomized complete block design with six replicates. Plants were watered daily with tap water. Soil temperature was monitored using HOBO Temp devices (Onset Computer Corporation, Bourne, MA) buried in the soil. After emergence, the seedlings were thinned to one per pot and fertilized with $6 \mathrm{~g}$ of slow-release fertilizer (Sierra 17-6-10 plus Minors; Scotts-Sierra Horticultural Products Company, Marysville, $\mathrm{OH})$. Four weeks after seeding, each pot was infested with $H$. schachtii by pipetting an aqueous suspension of 10,000 freshly hatched $\mathrm{J} 2$ into three holes $(\approx 3.0 \mathrm{~cm}$ deep and $1.5 \mathrm{~cm}$ wide) in the surface of the soil; the juvenile inoculum was collected and enumerated using a zinc chloride hatching protocol as previously described (7). Starting 3 weeks after infestation, each plant was fertilized with $50 \mathrm{ml}$ of a nutrient solution (Miracle Gro 15-30-15; Scotts Miracle-Gro Products, Marysville, OH) every 2 weeks. Eleven weeks after infestation $(\approx 1,185$ degree days and therefore at least two nematode generations) (3), plant tops were cut off at soil level and roots were removed from soil. Fresh and dry weights of shoots and roots were measured. Cysts were extracted from 350-g subsamples of the soil using the modified Fenwick flotation can method (4). Cysts were counted and then broken in a tissue homogenizer for egg counting. Egg parasitism was assessed by using a dissecting microscope to examine 100 randomly selected eggs per sample; these assessments were performed for trial 1 only. Eggs were considered parasitized if they appeared disrupted or disintegrated; nonparasitized eggs had a clear outline of a developing juvenile in the eggshell.

Data analysis. Cysts, eggs, and $\mathrm{J} 2$ were counted and the numbers were $\log (x+1)$ transformed to normalize the data. The transformed cyst and egg data and the plant mass data were subjected to analysis of variance and Fisher's least significant difference tests (SAS Institute, Cary, NC).

Nucleotide sequence data. Partial SSU rRNA gene and ITS sequences for the strains used in this study were determined: D. oviparasitica strain 50 SSU (AY970524) and ITS (AY970525); F. oxysporum strain 471 SSU (AY970526) and ITS (AY970527).

\section{RESULTS}

Isolation of $\boldsymbol{D}$. oviparasitica and $\boldsymbol{F}$. oxysporum. D. oviparasitica strain 50 and $F$. oxysporum strain 471 were obtained from 
cysts extracted from the suppressive $9 \mathrm{E}$ soil. These strains had $100 \%$ sequence identity to SSU rRNA genes whose levels previously were shown to correlate with $H$. schachtii suppressiveness (16); the lengths of the sequences compared in these analyses were 720 and 718 nucleotides for $D$. oviparasitica and $F$. oxysporum, respectively.

D. oviparasitica and $\boldsymbol{F}$. oxysporum greenhouse trials. Two replicate greenhouse trials were conducted to evaluate the ability of the fungal strains to suppress $H$. schachtii when added to nonsuppressive soil. As the results from both trials were similar, the data were combined for presentation (Table 1). D. oviparasitica strain 50 reduced $H$. schachtii population levels to those found in the suppressive 9E soil or lower. Specifically, cyst numbers were smallest in soil inoculated with $D$. oviparasitica strain 50 (treatment 2). Nematode egg numbers were smallest in soil inoculated with $D$. oviparasitica strain 50 and the suppressive soil (treatments 2 and 4). The lowest numbers of nematode juveniles were produced by $D$. oviparasitica strain 50 and the suppressive soil (treatments 2, 4, and 6). The highest percentage of egg parasitism occurred in treatments containing D. oviparasitica strain 50 and the suppressive soil (treatments 2, 4, and 6). F. oxysporum did not significantly reduce $H$. schachtii populations (treatment 1 ). D. oviparasitica strain Stirling (treatment 3) led to an increase in $H$. schachtii eggs but a decrease in $\mathrm{J} 2$ juveniles compared with the nonsuppressive soil. No differences were observed in the plant yield data except that the $9 \mathrm{E}$ soil consistently produced the lowest yields.

\section{DISCUSSION}

This study examined the role of $D$. oviparasitica and $F$. oxysporum in the $H$. schachtii suppressiveness exhibited by a southern Californian soil. Prior experimentation showed that $D$. oviparasitica and $F$. oxysporum rRNA gene levels positively correlated with high and minimal to moderate levels of suppressiveness, respectively (16). In the current study, D. oviparasitica strain 50 reduced the numbers of $H$. schachtii cysts, eggs, and juveniles to levels observed in the naturally suppressive soil or lower, whereas $F$. oxysporum did not significantly reduce $H$. schachtii populations. These results suggest that $D$. oviparasitica strain 50 plays a major role in the suppression of $H$. schachtii population development in this soil.

Several features of the experimental approach likely contributed to the successful outcome of these studies. The first was the culture-independent nature of the method used to identify microorganisms. Although our qPCR data showed that D. oviparasitica rRNA gene levels were $\approx 100$ times greater than rRNA gene levels from the other major cyst fungi (16), obtaining a pure culture of $D$. oviparasitica was a considerable challenge because it represented a minor fraction of the fungal strains obtained from $H$. schachtii cysts, likely due to its relatively slow growth on agar media. The second important feature of this approach was the attempt to identify microorganisms whose population levels correlated with the suppressiveness in soil-based experiments. This was accomplished by analyzing fungal rRNA genes from $H$. schachtii cysts obtained from a series of soil with various levels of suppressiveness (16).

Several characteristics of $D$. oviparasitica may contribute to its ability to suppress $H$. schachtii populations. D. oviparasitica has been described previously as an efficient egg parasite with a broad host range including several Meloidogyne spp., an Acrobeloides sp., H. schachtii, and Tylenchulus semipenetrans (10). The data presented in this report support this mode of action, because the $9 \mathrm{E}$ soil treatment along with all three $D$. oviparasitica strain 50 treatments generated the highest levels of egg parasitism. Certain strains of $D$. oviparasitica can produce networks and knobs in the presence of nematodes (6), suggesting that this fungus could be contributing to the suppressiveness through a predation mechanism. In addition, D. oviparasitica sporulates on and is frequently found near plant roots $(8,10)$. These characteristics, along with its apparent ability to grow saprophytically on roots (8), may contribute to its long-term survival in soil and, therefore, its ability to produce the stable $H$. schachtii suppressiveness exhibited by the 9E field soil (13).

This study also provided new information concerning the potential use of $D$. oviparasitica as a biological control agent and the nature of the $H$. schachtii suppressiveness in the 9E field soil. Adding D. oviparasitica strain 50 to the nonsuppressive soil before $H$. schachtii infestation led to a significant decrease in $H$. schachtii cyst and egg populations compared with the simultaneous addition of $D$. oviparasitica strain 50 and $H$. schachtii; therefore, establishment of sufficient population levels of this fungus in soil likely will be important for optimal nematode suppression. In addition, D. oviparasitica strain Stirling, which was isolated from Meloidogyne eggs, was not nearly as effective in reducing $H$. schachtii populations as D. oviparasitica strain 50 . This could have resulted from differences in host specificity between the strains or from the possible detrimental affects of long-term storage on the Stirling strain, which originally was isolated 28 years before this study (9).

Although $D$. oviparasitica strain 50 reduced $H$. schachtii numbers to those found in the suppressive 9E soil, differences in plant growth were not consistently observed. This likely was caused by several factors, including the manner in which the soils were infested with $H$. schachtii and the mode of action in which $D$. oviparasitica suppresses $H$. schachtii. First, in the greenhouse trials, all soils were infested with a large number of $H$. schachtii juveniles approximately 4 weeks after Swiss chard seed were sown. Although this increases treatment effects on $H$. schachtii numbers at the end of the trials, it also produces high nematode pressure early in the life of the plant, which may negate some of the beneficial effects of the added fungi in short-term greenhouse

TABLE 1. Heterodera schachtii numbers and plant mass as affected by Dactylella oviparasitica and Fusarium oxysporum in greenhouse trials ${ }^{\mathrm{y}}$

\begin{tabular}{|c|c|c|c|c|c|c|c|c|}
\hline \multirow[b]{2}{*}{ Treatment } & \multicolumn{4}{|c|}{ Weight (g) } & \multicolumn{3}{|c|}{ Number in $350 \mathrm{~g}$ of soil } & \multirow[b]{2}{*}{ Parasitized eggs (\%) } \\
\hline & Fresh shoot & Fresh root & Dry shoot & Dry root & Cysts & Eggs & $\mathrm{J} 2$ & \\
\hline 1. F. oxysporum strain 471 & $297 \mathrm{a}$ & $39 a$ & $30 \mathrm{a}$ & $18 \mathrm{a}$ & $122 \mathrm{bc}$ & $9,042 \mathrm{~b}$ & $6,300 \mathrm{ab}$ & $14.7 \mathrm{bc}$ \\
\hline 2. D. oviparasitica strain 50 & $300 \mathrm{a}$ & $38 \mathrm{a}$ & $28 \mathrm{a}$ & $20 \mathrm{a}$ & $73 \mathrm{~d}$ & $1,808 \mathrm{c}$ & 394 d & $27.2 \mathrm{a}$ \\
\hline 3. D. oviparasitica strain Stirling & $295 \mathrm{a}$ & $35 \mathrm{a}$ & $27 \mathrm{a}$ & $17 \mathrm{a}$ & $194 \mathrm{a}$ & 22,958 a & $9,727 \mathrm{a}$ & $12.7 \mathrm{c}$ \\
\hline 4. 9E soil (suppressive) & $81 \mathrm{~b}$ & $4 \mathrm{~b}$ & $9 \mathrm{~b}$ & $1 \mathrm{~b}$ & $116 \mathrm{bc}$ & $1,892 \mathrm{c}$ & $403 \mathrm{~d}$ & $21.2 \mathrm{ab}$ \\
\hline 5. Fumigated 9E (nonsuppressive) & $290 \mathrm{a}$ & $40 \mathrm{a}$ & $26 \mathrm{a}$ & $19 \mathrm{a}$ & $152 \mathrm{ab}$ & $10,525 \mathrm{~b}$ & $11,603 \mathrm{bc}$ & $3.5 \mathrm{~d}$ \\
\hline 6. D. oviparasitica strain $50+\mathrm{J} 2^{\mathrm{z}}$ & $323 \mathrm{a}$ & $39 \mathrm{a}$ & $32 \mathrm{a}$ & $19 \mathrm{a}$ & $99 \mathrm{c}$ & $4,517 \mathrm{~b}$ & $1,483 \mathrm{~cd}$ & $20.8 \mathrm{abc}$ \\
\hline
\end{tabular}

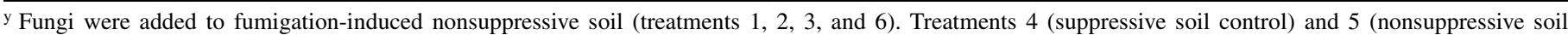
control) did not receive fungal inoculum. All treatments were planted with Swiss chard, infested with second-stage juveniles (J2) of $H$. schachtii, and assessed after two nematode generations. Results from two trials were similar and were combined. Values are the means of 12 replicate pots $\left(\approx 1,600 \mathrm{~cm}{ }^{3}\right.$ of soil/pot) except for egg parasitism values, which are the means of six replicates (parasitism was not assessed in the second trial). Numbers of cysts, eggs, and $\mathbf{J} 2 \mathrm{Were}$ log $(x+1)$ transformed to normalize the data. Means with the same letter are not significantly different $(P=0.05)$.

z Simultaneous addition. 
trials. Second, because we postulate that $D$. oviparasitica contributes to the suppressiveness mainly by egg parasitism, the fungus is likely to have little or no impact on the juvenile $H$. schachtii inoculum, which could lead to uniform plant damage across all treatments. This is supported by earlier trials in which no differences were observed between the numbers of $\mathrm{J} 2$ detected within the roots of Swiss chard grown in the suppressive 9E soil and a conducive soil 75 degree-days after soil infestation (5). Evidence supporting the egg parasitism mode of action comes from prior microscopic experimentation with another $D$. oviparasitica strain along with observations that $H$. schachtii numbers do not decrease in the suppressive 9E soil until the second nematode generation $(5,10,14)$. The poor plant growth in suppressive 9E soil likely was due to the presence of other pathogens or deleterious microorganisms, because this was the only treatment where the plants were grown in nonfumigated soil.

\section{ACKNOWLEDGMENTS}

The project was supported by the National Research Initiative of the USDA Cooperative State Research, Education and Extension Service, grant number 2003-35316-13824. This research also was supported in part by grants from the University of California Integrated Pest Management program and the University of California Center for Pest Management Research and Extension. We thank J. Darsow for technical assistance.

\section{LITERATURE CITED}

1. Becker, J. O., Ohr, H. D., Grech, N. M., and Sims, M. E. 1998. Evaluation of methyl iodide as a soil fumigant in container and small field plot studies. Pestic. Sci. 52:58-62.

2. Borneman, J., Chrobak, M., Vedova, G. D., Figueroa, A., and Jiang, T. 2001. Probe selection algorithms with applications in the analysis of microbial communities. Bioinformatics 17:S39-S48.
3. Caswell, E. P., and Thomason, I. J. 1991. A model of egg production by Heterodera schachtii (Nematoda: Heteroderidae). Can. J. Zool. 69:20852088.

4. Caswell, E. P., Thomason, I. J., and McKinney, H. E. 1985. Extraction of cysts and eggs of Heterodera schachtii from soil with an assessment of extraction efficiency. J. Nematol. 17:337-340.

5. Gao, X., and Becker, J. O. 2002. Population development of both sexes of Heterodera schachtii is diminished in a beet cyst nematode-suppressive soil. Biol. Control 25:187-194.

6. Koning, G., Hamman, B., and Eicker, A. 1996. The efficacy of nematophagous fungi on predaceous nematodes in soil compared with saprophagous nematodes in mushroom compost. S. Afr. J. Bot. 62:49-53.

7. Sheperd, A. M. 1970. Extraction and estimation of Heterodera. Pages $23-$ 33 in: Laboratory Methods for Work with Plant and Soil Nematodes. J. F. Southey, ed. Her Majesty's Stationery Office, London.

8. Stirling, G. R. 1979. Techniques for detecting Dactylella oviparasitica and evaluating its significance in field soils. Nematology 11:99-100.

9. Stirling, G. R., and Mankau, R. 1978. Dactylella oviparasitica, a new fungal parasite of Meloidogyne eggs. Mycology 70:774-783.

10. Stirling, G. R., and Mankau, R. 1979. Mode of parasitism of Meloidogyne and other nematode eggs by Dactylella oviparasitica. Nematology 11:282-288

11. Valinsky, L., Della Vedova, G., Jiang, T., and Borneman, J. 2002. Oligonucleotide fingerprinting of rRNA genes for analysis of fungal community composition. Appl. Environ. Microbiol. 68:5999-6004.

12. Valinsky, L., Della Vedova, G., Scupham, A. J., Alvey, S., Figueroa, A., Yin, B., Hartin, J., Chrobak, M., Crowley, D. E., Jiang, T., and Borneman, J. 2002. Analysis of bacterial community composition by oligonucleotide fingerprinting of rRNA genes. Appl. Environ. Microbiol. 68:3243-3250.

13. Westphal, A., and Becker, J. O. 1999. Biological suppression and natural population decline of Heterodera schachtii in a California field. Phytopathology 89:434-440.

14. Westphal, A., and Becker, J. O. 2000. Transfer of biological soil suppressiveness against Heterodera schachtii. Phytopathology 90:401-406.

15. Westphal, A., and Becker, J. O. 2001. Components of soil suppressiveness against Heterodera schachtii. Soil Biol. Biochem. 33:9-16.

16. Yin, B., Valinsky, L., Gao, X., Becker, J. O., and Borneman, J. 2003. Identification of fungal rDNA associated with soil suppressiveness against Heterodera schachtii using oligonucleotide fingerprinting. Phytopathology 93:1006-1013. 